\title{
Establishment of an Efficient BAC Transgenesis Protocol and its Application to Functional Characterization of the Mouse Brachyury Locus
}

\author{
Kuniya ABE 1, 4), Masaaki HAZAMA2), Hideki KATOH ${ }^{3)}$, \\ Ken-ichi YAMAMURA4, 5), and Misao SUZUKI5)
}

\begin{abstract}
${ }^{1)}$ Research \& Development Team for Mammalian Cellular Dynamics, BioResource Center, RIKEN Tsukuba Institute, 3-1-1 Koyadai, Tsukuba, Ibaraki 305-0074, ${ }^{2)}$ Department of Biological Sciences, Kyoto University Faculty of Medicine, Yoshidahonmachi, Sakyo-ku, Kyoto 606-8501, ${ }^{3}$ Experimental animals Institute, Hamamatsu University School of Medicine, 1-20-1 Handayama, Hamamatsu, Shizuoka 431-3192,

4)Institute of Molecular Embryology and Genetics, Kumamoto University, 4-24-1 Kuhonji, Kumamoto 862-0976, and ${ }^{5)}$ Center for Animal Research and Development, Kumamoto University, 1-1-1 Honjo, Kumamoto 860-0811, Japan
\end{abstract}

\begin{abstract}
Transgenesis using large DNA such as YAC or BAC has extended the range of applications in functional genomics. Here we describe an efficient $B A C$ transgenesis protocol using a simple BAC DNA preparation method adopted from YAC DNA purification methods. This method allowed us to isolate BAC DNA from small scale culture of BACcontaining cells in sufficient quantity and purity for microinjection. More than 40 founders have been produced with linearized BAC DNA prepared by this method, and $85 \%$ of them contained intact BAC transgenes. In contrast, when circular BAC DNA was injected, an approximately three-fold reduction of transgene integration rate was observed and fewer intact transgene integrations were obtained. A line of transgenic mice carrying a 170-kb $B A C$ clone generated in this way successfully rescued tail and embryonic lethality phenotypes of the mouse Brachyury $(\mathrm{T})$ mutants, further demonstrating the utility of this method in functional analysis of the mouse genome.
\end{abstract}

Key words: BAC, development, T-locus, transgenesis

\section{Introduction}

Transgenic technology has been extremely useful and successful for studying functions of genes of interest at an organism level. However, there are several technical limitations in conventional transgenic techniques. Since introns and essential regulatory elements required for correct in vivo expression tend to be omitted in the constructs, transgene expression often fails to follow the expression patterns of the corresponding endogenous gene. The chromosome 'position-effect' affects foreign gene expression, depending on the chromosomal integration site, compromising the transgene expression. In addition, the maximum size of the transgene is only

(Received 10 November 2003 / Accepted 25 February 2004)

Address corresponding: K. Abe, Research \& Development Team for Mammalian Cellular Dynamics, BioResource Center, RIKEN Tsukuba Institute, 3-1-1 Koyadai, Tsukuba, Ibaraki 305-0074, Japan 
$40-50 \mathrm{~kb}$, due to constraints on the insert length that can be cloned in phage or cosmid vectors. These limitations can be overcome by using cloning systems which accommodate submegabase DNA such as YAC (yeast artificial chromosome) or BAC (bacterial artificial chromosome) in the generation of transgenic mice (reviewed by Giraldo and Montoliu [7]). The ability to introduce large size DNA into mouse germ lines should help in attempts to isolate responsible genes for existing mutations, or induced mutations generated through the efforts of several 'large scale' mutagenesis projects operating in international mouse communities [11].

Although BAC DNA can be easily isolated by conventional plasmid preparation protocol for analytical work, care must be taken in preparing intact large DNA inserts for microinjection [5, 22, 24]. Takahashi et al. [22] compared three purification procedures for BAC DNA, and found that transgenic animals with intact BAC inserts were obtained only with BAC isolated by $\mathrm{CsCl}$ gradient ultra-centrifugation followed by linearization with restriction enzyme, pulsed field gel electrophoresis (PFGE) separation, and $\beta$-agarase digestion. We devised a similar but simpler procedure for BAC DNA isolation adopted from a YAC DNA purification method [17], and have generated 43 founder transgenic mice. Twenty nine mice in thirty four informative cases $(85.3 \%)$ seemed to have intact BAC transgenes. Genes contained in the BAC transgene appeared to be expressed in a correct fashion [8] and functional.

Mouse Brachyury (T) mutation is a semidominant mutation causing a short tail phenotype when heterozygous $(T /+)$, or embryonic lethality when homozygous. Another mutation, $t c t$, closely linked to the $T$ gene interacts with $T$ to cause a tailless phenotype in the double heterozygote, $T / t c t[3,6]$. The $T$ gene was identified by Herrmann et al. [9], but the molecular nature of the tct mutation remains to be elucidated $[1,12,14,15$, 16]. Here, we introduced a $170-\mathrm{kb}$ BAC containing the entire $T$ gene, and completely rescued the tail phenotypes of $T /+$ and of $T / t c t$. The embryonic lethal phenotype associated with the $T$-locus was also completely corrected by the presence of the BAC transgene.

\section{Materials and Methods}

$B A C$ clones: BAC clones used in this study were isolated from a mouse BAC library, CITBCJ7, supplied by Research Genetics (Cat.\# 96050, Huntsville, $\mathrm{AL}$, USA). Mouse genomic DNA is cloned into pBelloBAC11 vector [19] in this library. Details of BAC42, 132, and 213 clones were described by Kokubu et al. [13].

\section{Purification of BAC DNA for microinjection:}

Preparation of cell plugs: Bacterial cells containing BAC clone were cultured overnight in $10 \mathrm{ml}$ of LB with $12.5 \mu \mathrm{g} / \mathrm{ml}$ of chloramphenicol, collected by centrifugation at 5,000 rpm for $15 \mathrm{~min}$, and resuspended in $10 \mathrm{ml}$ of PIV buffer ( $1 \mathrm{M} \mathrm{NaCl}, 10 \mathrm{mM}$ Tris-Cl, $\mathrm{pH}$ 7.6). The suspension was centrifuged again, resuspended in $1.6 \mathrm{ml}$ of the PIV buffer, and warmed to $37^{\circ} \mathrm{C}$. The warmed suspension was mixed thoroughly with an equal volume of molten agarose, $1.6 \%$ InCert (FMC BioProducts, Rockland, ME), previously melted and warmed at $50^{\circ} \mathrm{C}$. One hundred microliter of the mixture was pipetted into the well of the agarose plug mold (LKB/Amersham Pharmacia, Piscataway, NJ), and the mold was stood at $4{ }^{\circ} \mathrm{C}$ to allow the agarose to solidify.

Lysozyme/RNase digestion: The agarose plug containing bacterial cells was placed in a $50 \mathrm{ml}$ plastic tube, and $1 \mathrm{ml}$ per plug of EC lysis solution, $6 \mathrm{mM}$ Tris-Cl, pH 7.6, $1 \mathrm{M} \mathrm{NaCl}, 100 \mathrm{mM}$ EDTA, 0.5\% Brij $58,0.2 \%$ deoxycholate, and $0.5 \%$ Sarkosyl were added. The mixture was shaken gently at room temperature for $15 \mathrm{~min}$, then the EC lysis solution was replaced with fresh EC lysis solution containing $1 \mathrm{mg} / \mathrm{ml}$ lysozyme and $20 \mu \mathrm{g} / \mathrm{ml}$ RNase, and incubated at $37^{\circ} \mathrm{C}$ overnight.

Proteinase $K$ digestion: The EC lysis solution was aspirated off and $1 \mathrm{ml}$ per plug of ESP buffer, $0.5 \mathrm{M}$ EDTA, pH 9.0, and 1\% Sarkosyl were added. The mixture was shaken gently at room temperature for 15 min, then the buffer was replaced with $1.5 \mathrm{ml}$ per plug of ESP containing $50 \mu \mathrm{g} / \mathrm{ml}$ of proteinase $\mathrm{K}$. The plugs were incubated at $50^{\circ} \mathrm{C}$ overnight with shaking. After proteinase $\mathrm{K}$ digestion, the plugs were washed twice with TE, $10 \mathrm{mM}$ Tris- $\mathrm{Cl}, \mathrm{pH} 7.5$ and $1 \mathrm{mM}$ EDTA, for 30 min each at room temperature, and stored at $4^{\circ} \mathrm{C}$ until use.

\section{Linearization of BAC clone:}

A: $\lambda$-Terminase treatment. Agarose plugs containing BAC DNA were washed in TE for $30 \mathrm{~min}$ twice, 
and washed three times in $10 \mathrm{mM}$ Tris-Cl, $\mathrm{pH} 7.5$. The plugs were soaked in $1 \times$ Terminase buffer without Terminase, and kept on ice for $1 \mathrm{~h}$. The composition of $5 \times \lambda$-Terminase buffer was $65 \mathrm{mM}$ Tris- $\mathrm{Cl}$, $\mathrm{pH} 8.0$, $15 \mathrm{mM} \mathrm{MgCl}_{2}, 375 \mathrm{mM} \mathrm{KCl}, 0.05 \%$ Triton X-100, 5 mM ATP, $2.5 \mathrm{mM}$ EDTA, $30 \mathrm{mM} \beta$-mercaptoethanol, and $25 \mathrm{mM}$ spermidine. One agarose plug was placed in a tube containing $100 \mu \mathrm{l}$ of $1 \times$ Terminase buffer, $0.5 \mathrm{mM}$ ATP, and 8 units of $\lambda$-Terminase (TAKARA Shuzo, Tokyo, Japan), and the tube was kept on ice for 1 to $2 \mathrm{~h}$, then incubated at $30^{\circ} \mathrm{C}$ for $6 \mathrm{~h}$ to $16 \mathrm{~h}$.

$\mathrm{B}$ : Use of rare cutting restriction enzyme. Uncut BAC clone was separated from the $E$. coli chromosome on PFGE: $0.5 \mathrm{X}$ TBE, $1 \%$ low melting point (LMP) agarose, SeaPlaque GTG (FMC BioProducts, Rockland, $\mathrm{ME})$. An agarose fragment containing BAC was excised, and washed twice in $1 \times$ buffer appropriate for restriction digestion for $30 \mathrm{~min}$. The agarose block was soaked in restriction enzyme solution ( $60 \mathrm{units} / \mathrm{ml})$ in a test tube, incubated on ice for $1 \mathrm{~h}$, and transferred to a $37^{\circ} \mathrm{C}$ incubator for overnight incubation. The agarose plug was inserted into a slot of another pulsed field gel, sealed with $1 \%$ LMP agarose and subjected to PFGE.

Pulsed-Field Gel separation of BAC insert: Agarose plugs containing linearized BAC DNA were loaded onto a preparative pulsed field gel of $0.5 \mathrm{X} \mathrm{TBE}$, and $1 \%$ SeaPlaque GTG agarose. Pulsed field gel electrophoresis was performed under conditions optimized to separate the BAC from the E. coli genome. After the PFGE run, marker lanes on either side of the preparative lane as well as about $5 \mathrm{~mm}$ of the preparative lane were cut off and stained with ethidium bromide. The position of the BAC band was marked with a sterile razor blade, and the part of the preparative lane containing the BAC DNA was excised. The excised gel slice was twice equilibrated in at least 10 volumes of the YAC buffer $(10 \mathrm{mM}$ Tris- $\mathrm{Cl}, \mathrm{pH} 8.0,0.1 \mathrm{mM}$ EDTA, $100 \mathrm{mM} \mathrm{NaCl}, 30 \mu \mathrm{M}$ spermine, $70 \mu \mathrm{M}$ spermidine) for $30 \mathrm{~min}$, then at $4^{\circ} \mathrm{C}$ for $16 \mathrm{~h}$. The gel slice was placed into a $2.0 \mathrm{ml}$ Eppendorf tube, and the remaining buffer was removed with a micropipette. The agarose was melted at $68-70^{\circ} \mathrm{C}$ for $15 \mathrm{~min}$ or longer. The agarose should completely melt into the solution at this step. The tube was placed in a $42^{\circ} \mathrm{C}$ water bath and incubated for $15 \mathrm{~min}$. An equal volume of $\beta$ agarase solution, $3 \%$ sucrose in the YAC buffer containing $\beta$-agarase (NEB, Beverly, MA), prewarmed at $42^{\circ} \mathrm{C}$ was added into the agarose solution. Four units of $\beta$-agarase should be added per $100 \mu \mathrm{l}$ of molten agarose. After incubation at $40^{\circ} \mathrm{C}$ for $-3 \mathrm{~h}$, the tube was spun at 5,000 rpm for $5 \mathrm{~min}$ at room temperature. The supernatant was transferred to a Microcon-100 filtration device (Amicon, Danvers, MA) with a wide bore pipette tip, spun at 4,000 rpm for $5 \mathrm{~min}$ and washed twice with YAC buffer. The DNA solution in the upper chamber of the Microcon-100 was collected, and this solution was directly used for microinjection. To determine concentration and to check the integrity of the BAC DNA, a small portion of the DNA solution was electrophoresed on a pulsed field gel and compared with known amounts of standard DNA, e.g. $\lambda$ DNA.

To isolate circular BAC DNA for microinjection, BAC DNA was obtained from a $500 \mathrm{ml}$ culture of BACcontaining bacteria using a QIAGEN Large Construct Isolation kit (QIAGEN, K.K., Tokyo, Japan) according to supplier's instructions.

Injection into mouse fertilized eggs: $\mathrm{BAC}$ transgene was microinjected into the male pronuclei of fertilized eggs obtained from C57BL/6 J mating [20]. A total of two to three hundreds eggs were regularly used for injection of each BAC DNA construct. Transgenic mice were screened using genomic DNAs collected from tail biopsy.

Genotyping by PCR: To detect BAC transgene integration, Southern blot analysis or PCR typing is generally performed. When BAC transgene is linearized by $\lambda$ Terminase at the cos site, the BAC transgene has small portions of BAC vector sequences at both ends of the insert. Primers used for amplification of the left end (T7 promoter seq. side) of the pBeloBAC11 vector were pBelo3; 5'-CAATGGAAGTCCGAGCTC and BAC2; 5'-GTCGACTCTAGAGGATC (product size, $450 \mathrm{bp}$ ), and primers for the right end (sp6 promoter seq. side) detection were pBelo1; 5'-CCGCTCACAATTCCACACA and pBelo2; 5'CCGGCAGTTTCTACACAT (product size; $600 \mathrm{bp}$ ). For typing the $T^{137}$ allele, TmycJ1 and TmycJ2 were used as described previously [1]. For detection of $t-$ haplotype DNA, TCP51, 5'-TGT GAT GAT GAG CTG ATC TTA, and TCP32, 5'-AAA CTC TGC AAT AGC AAG CTG were used. Since the amplified product has a TaqI polymorphism, the product from $t$-chromosome 
can be cleaved with TaqI, while the one from wild type chromosome cannot be digested.

Mice: The mouse strains used for the analysis of the Brachyury locus were original Brachyury $(T /+)$ mutant [6] and $t^{w 5}(t c t /+)$ [4]; both were kind gifts of Dr. H. Fujimoto of Mitsubishi Kagaku Institute of Lifesciences. $T^{137}$, a transgene-induced mutation of the Brachyury locus [1] was also used.

\section{FISH analysis of transgene integration:}

FISH analyses were performed according to the method of Watanabe et al. [21]. Chromosome spreads were hybridized with fluorescence-labeled BAC DNA probes and counterstained with propidium iodide. FISH signals were detected and photographed with a Nikon Microphoto FXA. Chromosomes were identified according to the $\mathrm{R}$ banding standards [20].

\section{Results}

\section{BAC DNA purification}

In contrast to high copy number plasmids, BAC clones are propagated as one or two copies per cell. To collect sufficient amount of BAC DNA for preparative work, large scale culture is usually needed. Although BAC DNA can be isolated by conventional method for plasmid preparation, there are considerable contaminations of bacterial genomic DNA or protein constituents in the BAC DNA preparation, which hamper subsequent cloning step or transgenic mouse production. Therefore, in general, one or two rounds of $\mathrm{CsCl}$ gradient purification of DNA from 1-2 1 culture of BAC-containing bacteria have been used for preparative work. Here we tried a simpler procedure for BAC DNA purification adopted from the YAC DNA purification method [17]. Cells containing BAC were embedded in agarose plugs, then treated with detergents and enzymes which remove the cell wall, proteins and other cellular materials, and genomic DNA as well as BAC DNA can be prepared in situ. The agarose plugs were loaded onto a pulsed field gel, and BAC DNA can be easily separated from genomic DNA. For linearization of BAC DNA, the cos site located within the BAC vector arm can be cleaved with $\lambda$-terminase. Linearized BAC DNA is excised from the PFGE gel, and the BAC DNA can be purified after $\beta$-agarase digestion followed by Microcon-100 concentration (see
Materials and Methods, Fig. 1A). As shown in Fig. 1B, intact BAC DNA of $-190-\mathrm{kb}$ in size was purified by the method described. BAC DNA sufficient for a microinjection experiment $(-1.5 \mu \mathrm{g})$ was purified from only a $10 \mathrm{ml}$ bacterial culture. BAC DNA purified by this method can be stored at $4^{\circ} \mathrm{C}$ for at least two weeks before microinjection.

\section{Generation of BAC transgenic mice}

Using BAC DNA prepared as described above, we generated 43 founder transgenic mice with 8 different BAC constructs (Table 1). Introduced BAC DNAs were linearized with $\lambda$-terminase except for the Vs-Cre construct which was digested with Sall. Concentration of BAC DNA for injection is usually adjusted to either 1 or $3 \mathrm{ng} / \mu \mathrm{l}$, as DNA of $5 \mathrm{ng} / \mu \mathrm{l}$ tended to give lower pups numbers (Table 1). The number of pups obtained after BAC DNA injection were generally lower than that with shorter transgene constructs. However, the integration efficiency or the frequency of transgenic mice among the born animals was similar to that obtained with short transgenic constructs $(23.8 \% ; 43$ transgenics in 181 pups). The sizes of the injected BAC DNA ranged from $75 \mathrm{~kb}$ to $180 \mathrm{~kb}$, but there were no apparent correlations between size of the construct and the integration efficiency, or the integrity of the integrated transgene. When linearized with $\lambda$ terminase, the left and right arms of BAC DNA can be detected separately by PCR typing. If both arms are positive by PCR typing, it is likely that the entire BAC insert is integrated into the mouse genome without fragmentation [22]. As shown in Table 1, 29 integrations in 34 informative cases (85.3\%) appeared to contain both right and left arms, suggesting that frequency of the fragmentation of the BAC DNA when integrated into the genome was not high with our BAC DNA preparations. Loss of one or both of the arms in subsequent generations was not observed for three transgenic lines tested. FISH analyses were performed for three BAC transgenic lines, and a single integration site of the transgene was observed for each BAC construct (Fig. 2, and not shown). In the case of the TBAC19, the transgene was integrated into chromosome 12. In one line of BAC9, integration was found on chromosome 14 , while in the other line the transgene was integrated near the centromeric part of chromosome 3 (Fig. 2). 
A

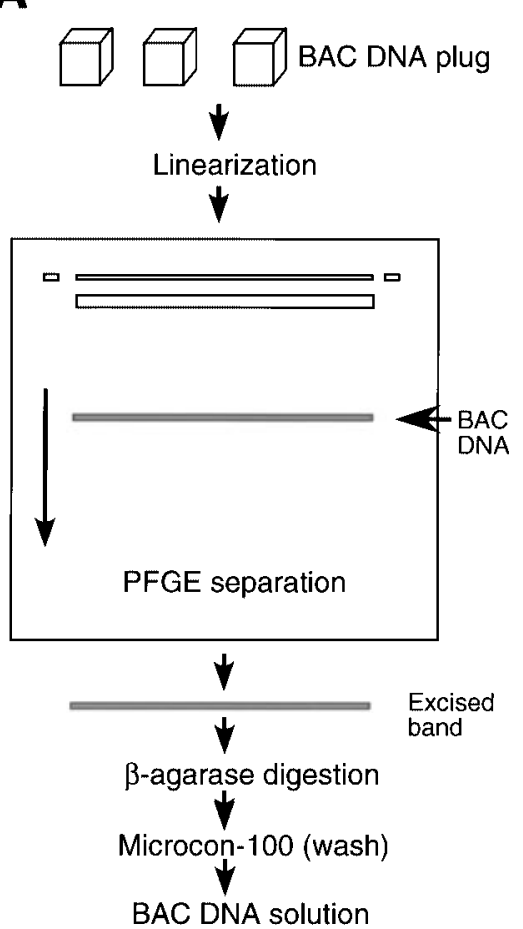

B

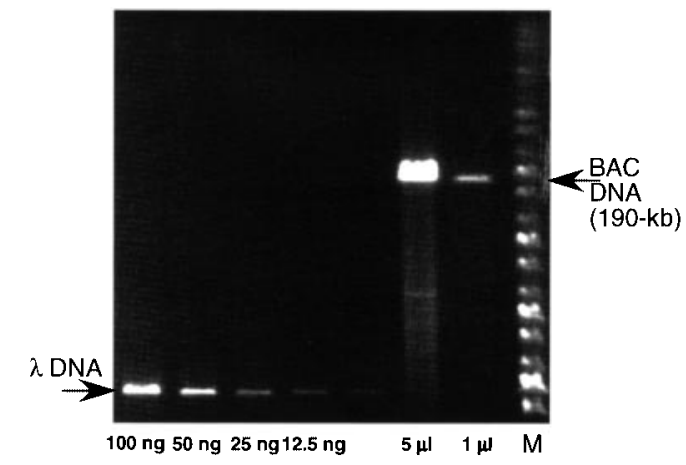

Fig. 1. Purification of BAC DNA for microinjection. A: BAC DNA are prepared in agarose plugs. BAC DNA are linearized by either lamda terminase or rare-cutting restriction enzyme, and separated from $E$. coli genomic DNA by pulsed field gel electrophoresis. A gel slice containing BAC DNA are digested by $\beta$-agarase and DNA is purified by a Microcon filtration device. B: BAC DNA purification method described here. A dilution series of lamda DNA was loaded next to the purified BAC DNA. One microliter of BAC DNA corresponded to about $1 \%$ of total amount of BAC DNA prepared by the method. M; molecular weight marker.

Functional rescue of Brachyury mutant phenotypes by $B A C$ transgene

We next applied this method for functional characterization of mutations associated with the mouse $T$ locus. One line of transgenic mouse harboring a 170$\mathrm{kb}$ fragment of BAC (Fig. 3A) containing the entire Brachyury or $T$ gene has been established (TBAC19 in Table 1). The copy number of the transgene was estimated to be 1-2 (not shown). The mouse Brachyury or $T$ gene is required for notochord development and maintenance. Homozygous $T / T$ embryos form insufficient axial and paraxial mesoderm and die at $10.5 \mathrm{dpc}$ due to failure in allantois-placental connection [3, 9]. Mice heterozygous for Brachyury mutation, T/+, exhibit a short tail phenotype, whereas a compound mouse carrying $T$ and $t c t$ ( $t$-complex tail interaction), a modifier of tail phenotype, show a tailless phenotype [3]. Stott et al. [18] reported that a $23-\mathrm{kb}$ genomic fragment con- taining the entire $T$ gene rescued the short tail phenotype of $T /+$, but failed to rescue the tailless phenotype of $T / t^{h 51}(T / t c t)$. The $T / t c t$ mouse carrying the $23-\mathrm{kb}$ genomic fragment showed short tail phenotype [10]. Rescue of the embryonic lethal phenotype has not been reported yet. First, we crossed a $T /+$ male with a +/+; TBAC transgenic female (Cross 1 in Table 2), and obtained 52 normal tail and 4 short tail offspring. If the BAC transgene is not present, theoretically one half of the offspring would be short tail, $T /+$ mice. Therefore, a bias toward normal tail phenotype suggests the possibility that the TBAC transgene complemented the short tail phenotype. If this is the case, out of 52 normal tail mice, 32 were +/+ and 20 were either $+/+$; TBAC or $T /$ +; TBAC. We next randomly selected three normal tail female mice carrying the TBAC transgene, and crossed them with the $t^{w 5} /+$ male. In two out of three cases, tailless mice carrying $t^{w 5}$ chromosome were obtained 
Table 1. List of BAC transgenic lines

\begin{tabular}{|c|c|c|c|c|c|c|}
\hline BAC clone & $\begin{array}{l}\text { size } \\
(\mathrm{kb})\end{array}$ & $\begin{array}{l}\text { conc. } \\
(\mathrm{ng} / \mu \mathrm{l})\end{array}$ & $\begin{array}{l}\text { born } \\
\text { pups }\end{array}$ & $\begin{array}{c}\text { integrated } \\
\text { total }(\%)\end{array}$ & $\mathrm{L}$ arm & $\mathrm{R}$ arm \\
\hline \multicolumn{7}{|c|}{ BAC insert prepared by method $1^{\dagger}$} \\
\hline 578-N15 & 130 & 1,3 & 27 & $15(55.6)$ & 15 & 14 \\
\hline 558-M23 & 180 & 5 & 24 & $4(16.7)$ & 4 & 3 \\
\hline BAC9 & 165 & 5 & 13 & $2(15.4)$ & 2 & 2 \\
\hline TBAC19 & 170 & 5 & 9 & $1(11.1)$ & 1 & 1 \\
\hline BAC132 & 100 & 1,3 & 20 & $3(15.0)$ & 3 & 2 \\
\hline BAC213 & 75 & 1,3 & 14 & $3(21.4)$ & 3 & 3 \\
\hline BAC42 & 140 & 1,3 & 19 & $6(31.6)$ & 5 & 5 \\
\hline \multirow[t]{2}{*}{$*$ Vs-Cre } & 140 & 1,3 & 55 & $9(16.4)$ & NA & NA \\
\hline & & & 181 & $43(23.8)$ & & \\
\hline \multicolumn{7}{|c|}{ BAC insert prepared by method $2^{\dagger \dagger}$} \\
\hline 309-M19 & 140 & 1,3 & 19 & $2(10.5)$ & 2 & 1 \\
\hline \multirow[t]{2}{*}{$100-\mathrm{G} 24$} & 150 & 1,3 & 15 & $1(6.7)$ & 1 & 0 \\
\hline & & & 34 & $3(8.8)$ & & \\
\hline
\end{tabular}

*Linearized with Sall digestion. Left and right arm of the BAC clones are not present in this case. Others were linearized with $\lambda$ terminase. NA; not applicable. Method 1 ; Insert DNA were prepared in agarose plug, linearized, separated on PFGE and released from agarose by agarase digestion. ${ }^{\dagger}$ Method 2; BAC DNA was isolated by QIAGEN Large Construct Isolation kit, and circular BAC DNA was injected.

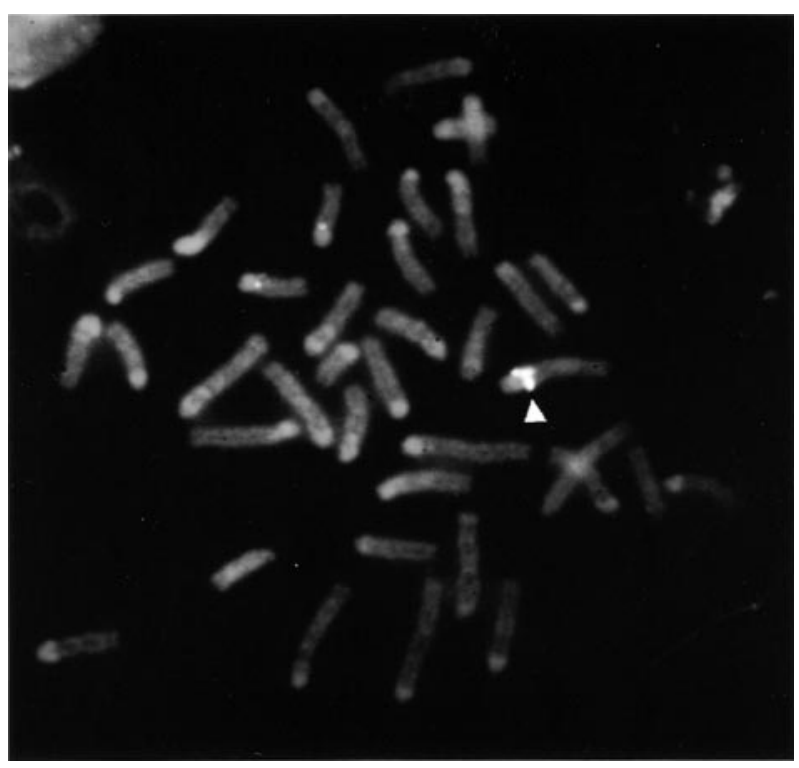

Fig. 2. FISH analysis of BAC transgene integration. A BAC clone isolated from the mouse quaking locus (BAC9 in Table 1) was fluorescence-labeled and hybridized to mouse chromosome spreads of a transgenic animal carrying the BAC9 transgene. In this case, the transgene was integrated into chromosome 3 (arrow head).
(Table 2, Cross 1b). The $T$ and + allele could not be distinguished in this cross as the classical $T$ mutation carries a deletion of $>200 \mathrm{~kb}$ at the $T$ locus. However, we believe that the genotype of the tailless mice must be $T / t^{w 5}$, since $+/+, T /+$ or $t^{w 5} /+$ mice never show a tailless phenotype [3]. This fact in turn suggests that the genotype of the females 1 and 2 used in Cross $1 b$ were likely to be $T /+$, and that the short tail phenotype of the $T /+$ was complemented by the TBAC transgene. Overrepresentation of normal tail offspring from females 1 and 2 also suggests that tailless phenotype of $T / t^{w 5}$, possibly present in the offspring, were rescued by the TBAC transgene. To obtain further evidence for the functional rescue of the tail phenotype by the BAC transgene, we next used $T^{137}$ allele, a transgene-induced null allele of the $T$ locus [1]. The $T^{137} /+$ heterozygote has a short tail, and shows a tailless phenotype when it is crossed with the complete $t$-haplotype mice such as $t^{w 5}$, which carry the tct mutation. Since $T^{137}$ is a transgene-insertional mutation, the genotype can be easily typed with PCR. As shown in Cross 2, the TBAC transgene indeed rescued the short tail phenotype of $T^{137} /+$. Although +/+; TBAC mice should contain more 
Table 2. Genotypes and phenotypes of offspring from crosses between $T / t$ mutants and $+/+$; TBAC

\begin{tabular}{|c|c|c|c|}
\hline & \multicolumn{3}{|c|}{ Tail phenotypes } \\
\hline & normal & short & absent \\
\hline \multicolumn{4}{|c|}{ Cross $1(+/+;$ TBAC $\times T /+)$} \\
\hline & $52 *$ & $4 * *$ & 0 \\
\hline \multicolumn{4}{|c|}{ Cross $1 \mathrm{~b}$ (normal tail; TBAC from Cross $1 \times t^{w 5} /+$ ) } \\
\hline female 1 & 9 & 0 & $1 * * *$ \\
\hline female 2 & 7 & 0 & $1 * * *$ \\
\hline female 3 & 8 & 0 & 0 \\
\hline \multicolumn{4}{|c|}{ Cross $2\left(+/+;\right.$ TBAC $\left.\times T^{137} /+\right)$} \\
\hline \multicolumn{4}{|c|}{ Genotype } \\
\hline$+/+$ & 3 & 0 & 0 \\
\hline +/+; TBAC & 6 & 0 & 0 \\
\hline$T^{137} /+;$ TBAC & 4 & 0 & 0 \\
\hline$T^{137 /+}$ & 0 & 10 & 0 \\
\hline \multicolumn{4}{|c|}{ Cross $3\left(T^{137} /+;\right.$ TBAC $\left.\times T / t^{w 5}\right)$} \\
\hline \multicolumn{4}{|c|}{ Genotype } \\
\hline$T^{137} / t^{w 5} ; \mathrm{TBAC}$ & 6 & 0 & 0 \\
\hline$T^{137} / T ;$ TBAC & 5 & 0 & 0 \\
\hline$t^{w 5} /+;$ TBAC & 5 & 0 & 0 \\
\hline$t^{w 5} /+$ & 1 & 0 & 0 \\
\hline$T /+;$ TBAC & 1 & 0 & 0 \\
\hline$T /+$ & 0 & 2 & 0 \\
\hline$T^{137} / t^{w 5}$ & 0 & 0 & 3 \\
\hline \multicolumn{4}{|c|}{ Cross $4\left(T^{137} / t^{w 5} ;\right.$ TBAC $\times T^{137} / t^{w 5} ;$ TBAC $)$} \\
\hline \multicolumn{4}{|c|}{ Genotype } \\
\hline$T^{137} / T^{137} ; \mathrm{TBAC}$ & 6 & 0 & 0 \\
\hline$T^{137} / t^{w 5} ;$ TBAC & 7 & 0 & 0 \\
\hline$T^{137} / t^{w 5}$ & 0 & 0 & 4 \\
\hline
\end{tabular}

* Of these 52 normal tail mice, 32 mice did not carry the TBAC transgene, while 20 mice carried the TBAC transgene. Thus these 20 mice can be genotyped as either +/+; TBAC or T/+; TBAC. **These short tail mice can be genotyped as $T /+$, as the $T /+$ mice have a short tail clearly distinguishable from that of the wild-type mice on this genetic background. ***These zero tail mice had the $t^{w 5}$ chromosome, thus likely to be $T / t^{w 5}$.

than three copies of the Brachyury gene, these animals showed normal morphological phenotypes. To test whether the BAC can rescue the tailless phenotype produced by interaction between $T$ and $t c t$, a $T / t^{w 5}$ zero tail male was crossed with a $T^{137} /+$; TBAC female (Cross 3 in Table 2). Three mice genotyped as $T^{137} / t^{w 5}$ were tailless as expected. However, six mice with $T^{137} / t^{w 5}$ genotype had completely normal tails in the presence of the TBAC transgene, indicating functional correction of the tailless phenotype by BAC. Genotypes of two short tail mice and one normal tail with the BAC transgene are likely to be $T /+$ and $T /+$; TBAC, respec- tively in this breeding scheme. Therefore it should be noticed that five normal tail mice with the TBAC transgene but not with $t^{w 5}$ chromosome could have the $T^{137} / T$; TBAC genotype, suggesting that the embryonic lethality may also be rescued by the transgene. To investigate this point further, $T^{137} / t^{w 5}$; TBAC male and female mice produced from Cross 3 were mated and their offspring were examined (Cross 4 in Table 2). The results demonstrate that the embryonic lethality of the $T^{137} / T^{137}$ was indeed rescued by TBAC19. Absence of the $t^{w 5} / t^{w 5}$ or the $t^{w 5} / t^{w 5}$; TBAC19 mice can be interpreted by the embryonic lethality of $t^{w 5}$ manifested at the gastrulation stage [4]. Recombination between $T$ or wild type chromosome and the $t^{w 5}$ haplotype was negligible due to chromosome inversion associated with the $t^{w 5}$ haplotype [3].

\section{Discussion}

More than 40 founder transgenic mice have been produced with BAC DNA prepared by the method described in this paper. There is a tendency for the number of pups to be fewer in comparison with conventional transgenesis when BAC DNA, especially of high concentration, was injected. However, integration frequency in the pups was sometimes even higher than regular transgenesis, and the overall number of transgene integrations was comparable to that obtained with short transgene constructs. Moreover, PCR assay with primers corresponding to right and left arms of linearized BAC DNA revealed that most of $(85.3 \%)$ the transgenic mice contained intact BAC inserts. In contrast, circular BAC DNA prepared by alkali lysis followed by column purification gave a three-fold lower transgene integration rate and fewer intact transgene integrations. Antoch et al. [2] reported that injection of circular BAC DNA yields transgenic offspring at rates comparable to linearized, purified DNA. Thus it should be possible to use circular DNA for microinjection, but there is an argument that undesirable DNA might be generated by random recombination within constructs before integration when circular DNA is used [7].

These data altogether suggest that the method described in this paper could produce linearized BAC DNA with sufficient quantity, purity and integrity for microinjection experiments. Preparation of sufficient amount of intact BAC DNA for microinjection has been 


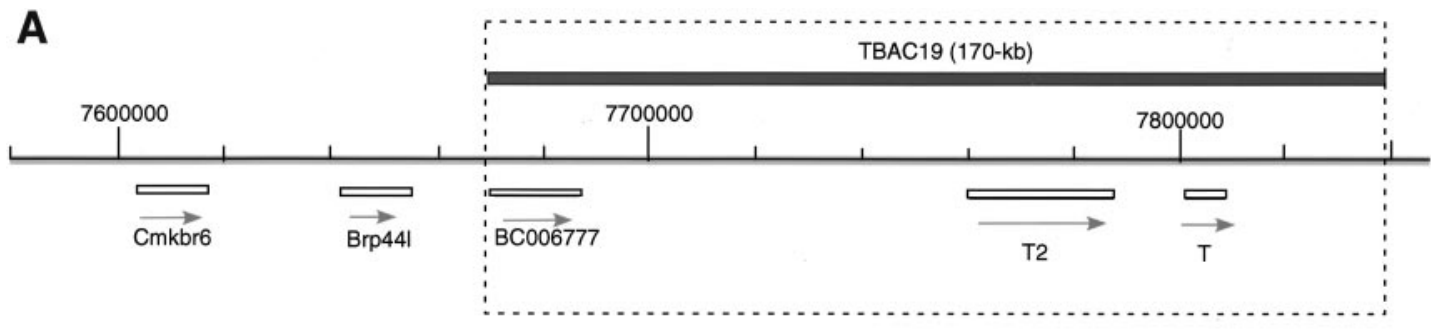

B
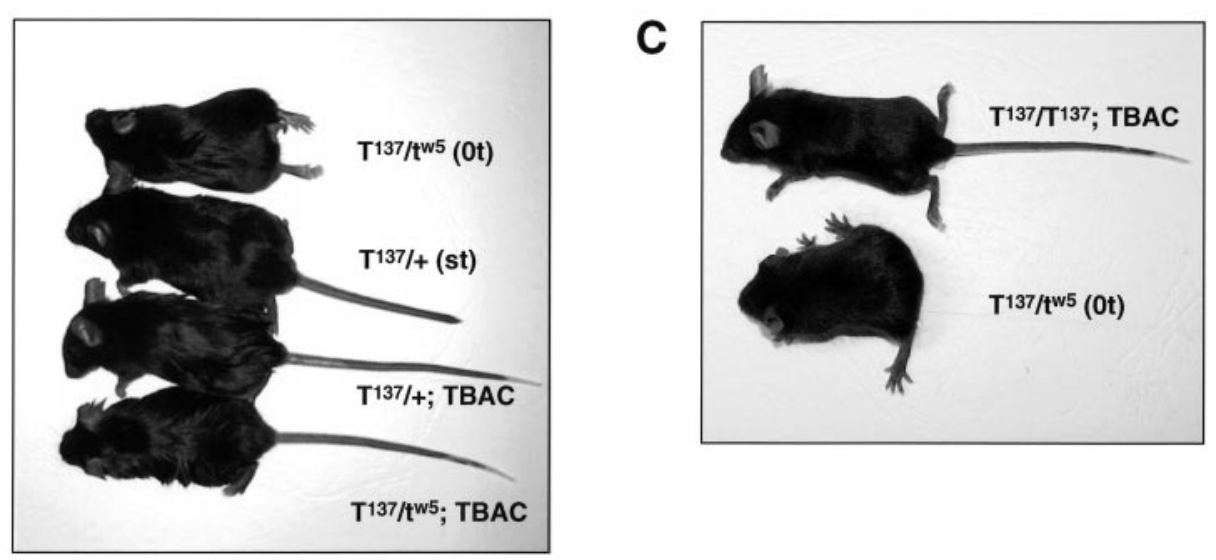

Fig. 3. A: A genomic map around the mouse $T$ locus. Numbers shown above the line are nucleotide positions of mouse chromosome 17; this information was retrieved from UCSC mouse genome browser (http:// genome.ucsc.edu/). Transcription units mapped in this genomic region are shown under the line: T, Brachyury, NM_009309; T2, Brachyury the Second, NM_013682; BC006777, Mouse mRNA, similar to CG5104 gene product, BC006777; Brp44l, Brain protein 44 like, NM_018819; Cmkbr6; carbon catabolite repression 6 homolog, NM_009835. Position of TBAC19 used for the rescue experiment was determined by sequencing both ends of the insert and mapping onto the $\mathrm{C} 57 \mathrm{BL} / 6 \mathrm{~J}$ genome sequence data. B: Tail phenotypes of $T$ mutants and rescued animals. $T^{137} / t^{w 5}$ showed zero (absent) tail (0t), and $T^{137} /+$ had short tail (st). In contrast, $T^{137} /+$; TBAC and $T^{137} / t^{w 5}$; TBAC mice showed normal tail phenotype. C: Morphology of rescued animal. $T^{137} / T^{137}$; TBAC had normal tail and normal gross appearance.

a laborious task. BAC DNA isolation protocol usually involves large scale, i.e. one to two liter bacterial culture followed by $\mathrm{CsCl}$ density gradient purification and/ or column chromatography $[5,24 ;$ http:// www.med.umich.edu/tamc/BACDNA.html]. The integration efficiency or frequency of transgene fragmentation was not described in detail in these studies. Takahashi et al. [22] compared three methods and found that integration of intact DNA occurred only when the BAC DNA was isolated by $\mathrm{CsCl}$ gradient centrifugation followed by linearization with restriction enzyme, PFGE separation, and $\beta$-agarase digestion. They found that four animals out of twelve transgenic founders $(33.3 \%)$ possessed both ends of the BAC transgene. In contrast, more than $80 \%$ of our transgenic mice carried intact BAC DNA. Therefore our method is apparently simpler and requires less resources and labor, and may serve as a better alternative to the existing protocols.

Stott et al. [18] reported that a single copy transgene of a $23-\mathrm{kb}$ genomic fragment containing the entire $T$ gene transcription unit could rescue the short tail defect of $T /+$ mice, but failed to complement $T / t c t$ and $T / T$ phenotypes $[10,18]$. The T/tct mouse carrying the 23$\mathrm{kb}$ genomic fragment showed the short tail phenotype [10]. In contrast, our transgenic mice harboring $T$ genecontaining BAC could rescue both short tail phenotypes of $T /+$ and $T^{137} /+$, and the tailless phenotype of $T^{137} / t^{w 5}$ (Fig. 3). The TBAC transgene probably rescued the tailless phenotype of the $T / t^{w 5}$, since the majority of the offspring from females 1 and 2 of the Cross $1 \mathrm{~b}$ in Table 2 exhibited the normal tail phenotype. The $T$ allele carries a large $(>200 \mathrm{~kb})$ deletion with undefined breakpoints, which covers the entire $T$ transcription unit and probably several other genes, while the $T^{137}$ allele 
is the null allele only for the $T$ gene $[1,9]$. Both alleles interact with $t c t$ to cause the tailless phenotype. The TBAC transgene used in this study for the first time rescued the embryonic lethality associated with the $T^{137} /$ $T^{137}$ or $T / T^{137}$ mutations. Differences between our result and that of Stott et al. [18] can be reconciled as follows, 1) the 23-kb transgene confers only partial or reduced activity of the $T$ gene product, which is sufficient for complementation of the $T /+$ tail defect, but not for the tailless defect or embryonic lethality, whereas the TBAC transgene has full activity of the $T$ product; or 2) there may be other gene(s) involved in the tailless defect or embryonic lethality located near the $T$ gene. Since the original $T$ mutation deletes the $T$ and other neighboring genes, the phenotype of the original Brachyury mutation may be a sum of those of the $T$ and other mutations, and these combined phenotypes can be rescued by the 170-kb BAC, but cannot be corrected by the 23-kb DNA containing the $T$ gene only. Rennebeck et al. $[15,16]$ reported the presence of a gene designated as $T 2$ located $-40 \mathrm{~kb}$ upstream of the Brachyury gene, and that a transgene-insertional mutation of the $T 2$ gene resulted in embryonic lethality at 11.5 dpc. Rennebeck et al. [16] considered the $T 2$ gene as a strong candidate for $t c t$. Whether $t c t$ is an allele of the $T$ locus or represents a distinct locus adjacent to the $T$ gene, such as $T 2$ gene, remains to be elucidated [12, 14-16]. Detailed characterizations of the genomic region covered by the TBAC19 and further analysis of genes in and around this genomic region will be important for understanding the functional relationships between the $T, T 2$ and possibly tct genes. The BAC transgenesis method presented in this paper should facilitate functional analyses of the genomic region.

\section{Acknowledgments}

We thank Dr. T. Kondo for restriction mapping of the TBAC clone. We also thank Ms. M. Yuzuriha for technical assistance and genotyping of transgenic animals. This work was supported in part by the Ministry of Education, Culture, Sports, Science and Technology of Japan, with Special Coordinating funds for Promoting Science and Technology to KA.

\section{References}

1. Abe, K., Yamamura, K., and Suzuki, M. 2000. Molecular and embryological characterization of a new transgeneinduced null allele of mouse Brachyury locus. Mamm. Genome 11: 238-240.

2. Antoch, M.P., Song, E.-J., Chang, A.-M., Vitaterna, M.H., Zhao, Y., Wilsbacher, L.D., Sangoram, A.M., King, D.P., Pinto, L.H., and Takahashi, J.S. 1997. Functional identification of the mouse circadian Clock gene by transgenic BAC rescue. Cell 89: 655-667.

3. Bennett, D. 1975. The T-locus of the mouse: a review. Cell 28: 463-470.

4. Bennett, D. and Dunn, L.C. 1958. Effects on embryonic development of a group of genetically similar lethal alleles derived from different populations of wild house mice. $J$. Morph. 103: 135-158.

5. Chrast, R., Scott, H.S., and Antonarakis, S.E. 1999. Linearization and purification of BAC DNA for the development of transgenic mice. Transgenic Res. 8: 147150.

6. Chesley, P. 1935. Development of the short-tailed mutant in the house mouse. J. Exp. Zool. 70: 429-435.

7. Giraldo, P. and Montoliu, L. 2001. Size matters: use of YACs, BACs and PACs in transgenic animals. Transgenic Res. 10: 83-103.

8. Hazama, M., Watanabe, D., Suzuki, M., Mizoguchi, A., Pastan, I., and Nakanishi, S. 2002. Different regulatory sequences are required for parvalbumin gene expression in skeletal muscles and neuronal cells of transgenic mice. Mol. Brain Res. 100: 53-56.

9. Herrmann, B.G., Labeit, S., Poustka, A., King, T.R., and Lehrach, H. 1990. Cloning of the $T$ gene required in mesoderm formation in the mouse. Nature 343: 617-622.

10. Herrmann, B.G. 1995. The mouse Brachyury (T) gene. seminars in Dev. Biol. 6: 385-394.

11. Hrabe de Angelis, M.H., Flaswinkel, H., Rathkolb, B., Soewarto, D., Marschall, S., Heffner, S., Pargent, W., Wuensch, K., Jung, M., Reis, A., Richter, T., Alessandrini, F., Jakob, T., Fuchs, E., Kolb, H,. Kremmer, E., Schaeble, K., Rollinski, B., Roscher, A., Peters, C., Meitinger, T., Strom, T., Steckler, T., Holsboer, F., Klopstock, T., Gekeler, F., Schindewolf, C., Jung, T., Avraham, K., Behrendt, H., Ring, J., Zimmer, A., Schughart, K., Pfeffer, K., Wolf, E., and Balling, R. 2000. Genome-wide, large-scale production of mutant mice by ENU mutagenesis. Nat. Genet. 25: 444447.

12. Justice, M. and Bode, V. 1988. New evidence supporting the allelism of $T$ and tct. Mouse Newslett. 80: 168-169.

13. Kokubu, C., Wilm, B., Kokubu, T., Wahl, M., Rodrigo, I., Sakai, N., Santagati, F., Hayashizaki, Y., Suzuki, M., Yamamura, K.-I., Abe, K., and Imai, K. 2003. Undulated short-tail deletion mutation in the mouse ablates Paxl and leads to ectopic activation of neighboring $N k x 2-2$ in domains that normally express Paxl. Genetics 165, 299-307.

14. Nadeau, J.H., Varnum, D., and Burkart, D.1989. Genetic evidence for two $t$ complex tail interaction (tct) loci in $t$ 
haplotypes. Genetics 122: 895-903.

15. Rennebeck, G.M., Lader, E., Chen, Q., Bohm, R.A., Cai, Z.S. Faust, C., Magnuson, T., Pease, LR., and Artzt, K.1995. Is there a Brachyury the Second? Analysis of a transgene mutation involved in notochord maintenance in mice. Dev. Biol. 172: 206-217.

16. Rennebeck, G., Lader, E., Fujimoto, A., Lei, E.P., and Artzt, K. 1998. Mouse Brachyury the Second (T2) is a gene next to classical $T$ and a candidate gene for $t c t$. Genetics 150: 1125-1131.

17. Schedl, A., Grimes, B., and Montoliu, L. 1996. YACtransfer by micoroinjection. Methods Mol. Biol. 54: 293-306.

18. Stott, D., Kispert, A., and Herrmann, B.G. 1993. Rescue of the tail defect of Brachyury mice. Genes Dev. 7: 197-203.

19. Shizuya, H., Birren, B., Kim, U.-J., Mancino, V., Slepak, T. Tachiiri, Y., and Simon, M. 1992. Cloning and stable maintenance of 300-kilobase-pair fragments of human DNA in Escherichia coli using a F-factor-based vector. Proc. Natl. Acad. Sci. U.S.A. 89: 8794-8797.

20. Somssich, I.E. and Hameister, H. 1989. Standard karyotype of early replicating bands. pp. 580-581. In Genetic variants and strains of the laboratory mouse, Second ed. Edited by Lyon, M.F. and Searle, A.G. Oxford University Press, New York.

21. Suzuki, M., Abe, K., Yoshinaga, K., Obinata, M., Furusawa, M., and Abe, K. 1996. Specific arrest of spermatogenesis caused by apoptotic cell death in transgenic mice. Genes Cells 1: 1077-1086.

22. Takahashi, R., Ito, K., Fujiwara, Y., Kodaira, K., Kodaira, K., Hirabayashi, M., and Ueda, M. 2000. Generation of transgenic rats with YACs and BACs: Preparation procedures and integrity of microinjected DNA. Exp. Anim. 49: 229-233.

23. Watanabe, Y., Ebukuro, M., Yagami, K., Sugiyama, S., Ishida, J., Murakami, K., Nomura, T., and Katoh, H. 1996. Chromosomal maping of human angiotensinogen gene and human renin gene by fluorescence in situ hybridization (FISH) in transgenic mice. Exp. Anim. 45, 265-269.

24. Yang, X.W., Model, P., and Heintz,N. 1997. Homologous recombination based modification in Escherichia coli and germline transmission in transgenic mice of a bacterial artificial chromosome. Nat. Biotechnol. 15: 859-865. 